Research Article

\title{
Study case on controlled breeding and first growth steps of chiloscyllium puctatum
}

\begin{abstract}
Such study, conducted at Acquario di Cattolica (Rimini, Italy), lasted six months of observations on Chiloscyllium punctatum reproductive biology. It is an oviparous species present in many aquaria around the world, but the fishing effort, habitat destruction and constant samples taking have led to a drop in the number of wild populations (IUCN red list). Looking at the current low level of reproductive standard protocols, we tried to collect the greatest number of useful information in order to obtain a reproductive protocol. The couple of adults, cohabiting in a tank with other species, were breeding and maintained in stable environmental conditions (i.e. $\mathrm{T}^{\circ} \mathrm{C}, \%$ and $\mathrm{pH}$ ). When deposition occurred, the eggs were moved in 5 expository trays (Themes-5), ex-novo settled up. These trays allowed the monitoring of embryonic development till hatching $120 \pm 10$ days post deposition (dpd). Newborns were measured by total length (TL, $\mathrm{cm}$ ) to quantify the growth (Von Bertalanffy Growth Function, VBGF) and the growth rates (GR), therefore weaned from yolk sac. They were feeded 3 times per week, by a specific diet based on shrimp (Pandalus borealis), capelin (Mallotusvillosus), codfish (Merlucciusmerluccius) and mackerel (Scomberscombrus). Besides, it was setted a light gradient $(1 \mathrm{~lx}<x<10 \mathrm{~lx})$ on Themes-5 to assess the light influence on newborns growth. The VBGFs underlined significant differences about sizes and timelines to achieve sexual maturity between male and females $(p<0.05)$. Concerning different light conditions, we underlined no significant differences $(p>0.05)$. Shrimp $(P$. borealis: $3 \mathrm{cal} / 1 \mathrm{gr}$ ) resulted the food with the best performance. The adults produced 33 newborns depositing 2 eggs per week. These observations have made possible to provide useful information on shark deposition, hatching, diet and newborn growth.
\end{abstract}

Keywords: Sharks breeding, Biometry, Weaned diet, Light conditions, P. borealis, Growth rate, Growth curve, ex novo, Acquario di Cattolica, C. punctatum, Setted up, Von Bertalanffy, Growth function
Volume 3 Issue 2 - 2015

\author{
Giovanni Rossi, I Daniela Florio, I,2 Stefano \\ Gridelli I \\ 'Tropical and Sharks sector, Acquario di Cattolica, Italy \\ ${ }^{2}$ Department of Veterinary Medical Sciences (DIMEVET), \\ University of Bologna, Italy
}

Correspondence: Giovanni Rossi, Tropical and Sharks sector, Acquario di Cattolica, Centrosub Piombino,Via Trasimeno n.36, Arezzo, Tuscanay, Italy, Tel +39057527457,

Email yancsi@gmail.com

Received: September 18, 2015 | Published: November 09, 2015
Abbreviations: dpd, Days Post Deposition; T5, Main Tank; Themes-5, Expository Tanks; BW, Body Weight; TL, Total Length; ADF, Average Deposition Frequency; GR, Growth Rate; $\mathrm{T}{ }^{\circ} \mathrm{C}$, Temperature; \%, Salinity; $\mathrm{T}_{\mathrm{x}}$, Tanks; $\mathrm{P}_{\mathrm{x}}$, Pumps; VBGF, Von Bertalanffy Growth Function; GH Plot, Gulland \& Holt's plot; HSD, Tukey's Post-Hoc Test ; ANOVA, Analysis of Variance

\section{Introduction}

The shark's presence in controlled environment allows many scholars to conduct observations on specimens maintained in public aquaria or marine research institutes. The Elasmobranchii knowledge is still limited and many aspects regarding their biology, ecology and ethology are yet undiscovered. By the way, they are conducted ever more often studies in many aquaria around the world that allow to bypass obvious difficulties which are rising up during observation into the wild. ${ }^{1}$ Bamboo shark Chiloscyllium punctatum is an oviparous species present in many aquaria around the world, but the fishing effort, habitat destruction and constant samples taking have led to a drop in the number of wild populations. ${ }^{2}$ Looking at the current low level of reproductive standard protocols, since December 2013 till June 2014 at Acquario di Cattolica (Rimini, Italy), we tried to collect the greatest number of useful information from a couple of adults to obtain a functional reproductive protocol. We were paying attention to reproduce the controlled environment as much as similar to their natural habitat, ${ }^{3-6}$ so aiming to a correct maintenance of the optimal water chemical-physical conditions shown in Table $1,{ }^{7}$ studying for a formulated diet suitably to their feeding needs shown in Table
$2^{8-12}$ and taking regard to the influences of the maintenance in a controlled environment which, on sharks growth, it cannot be ignored because there are conflicting studies underlining the differences with their wild co-specific. ${ }^{13-16}$ Furthermore, an optimized reproductive protocol could be useful to promote species exchange activities between public aquaria and marine institutions, so reducing samples taking from nature. ${ }^{17,18}$ The main aim of this study was to produce a reproductive protocol of $C$. punctatum, although the target species is classified as least concernfrom Australian government who protect its territories; indeed it is listed as in decline. ${ }^{2}$ Anyway, during last years, C. punctatum has taken a more important commercial value as ornamental species for many public aquaria and private aquarists bring to the increase in demand and consequent decline of the resource into the wild. ${ }^{19}$ Within species safeguard-view, under the experimental conditions we setted up, we defined the following secondary aims to determine: the reproductive cycle and specimens life stages; the most efficient diet to wean newborns from yolk-sac; the more consonant lighting conditions; ${ }^{20,21}$ the biometrical averages of the eggs, newborns and adults; the newborns growth; the embryos development times; the egg-deposition frequency and the hatching times. Besides, we formulated four different experimental hypotheses: 1) Are different lighting conditions significantly inducing the normal development and hatching times? 2) Are different lighting conditions significantly inducing the newborns growth? 3) Are different nourishment sources producing significantly growth differences during the weaned period? 4) Is the assumption of vitamins inducing significantly the growth during the weaned period? 
Table I Water parameters guidelines from Mohan \& Aiken. ${ }^{7}$

\begin{tabular}{|c|c|c|}
\hline Parameters & Range & Unity \\
\hline Salinity & $25.0-35.0$ & g I-I (ppt) \\
\hline $\mathrm{pH}$ & $8.0-8.4$ & $\%$ of saturation \\
\hline DO & $85-98$ & NTU \\
\hline Turbidity & $<0.15$ & $\mathrm{mV}$ \\
\hline ORP & $250-380$ & $m g ~ I-I$ \\
\hline $\mathrm{NH}_{3}$ Unionized $\left(\right.$ At $\left.10{ }^{\circ} \mathrm{C}\right)$ & $<0.1$ & $m g ~ I-I$ \\
\hline $\mathrm{NH}_{3}$ Unionized $\left(\mathrm{At} 17^{\circ} \mathrm{C}\right)$ & $<0.2$ & mg I-I \\
\hline $\mathrm{NH}_{3}$ Unionized (At $\left.28^{\circ} \mathrm{C}\right)$ & $<0.3$ & mg I-I \\
\hline $\mathrm{NO}_{2-}^{-}$ & $<0.1$ & mg I-I \\
\hline $\mathrm{NO}_{3}^{-}$ & $<70.0$ & ufc $100 \mathrm{ml}-\mathrm{I}$ \\
\hline Total Coliform & $<1000$ & mg I-I \\
\hline $\mathrm{Cu}$ & $<0.01$ & mg I-I \\
\hline Zinc & $<0.01$ & mg I-I \\
\hline Nickel & $<0.01$ & mg I-I \\
\hline Iron & $<0.0$ & g I-I (ppt) \\
\hline
\end{tabular}

DO: Dissolved Oxygen; ORP: Oxidation Reduction Potential; $\mathrm{NH}_{3}$ : Ammonia; $\mathrm{NO}_{2}-$ : Nitrites; $\mathrm{NO}_{3}-$ : Nitrates; Cu: Copper; Zn: Zinc; Ni: Nickel; Fe: Iron.

\section{Materials and methods}

The breeding couple of $C$. punctatum $^{22,23}$ and their newborns were maintained in a unique tank system (Figure 1) composed from a main tank, called "The Casket of Neptune"(T5) which was hosting the couple of adults with many tropical fishes and the, ex novo made, five secondary trays called "Nursery themes" (Themes-5) which were hosting only newborn and eggs. The main tank T5 (Figure 2) had a water capacity of $40.000 \mathrm{~L}\left(40 \mathrm{~m}^{3}\right)$ and it was composed of 2 parts in communication between them. Instead, Themes-5 (Figure 3) had a water capacity of $27 \mathrm{~L}$, they were numbered from 1 to 5 and they were provided with an anti-skip each as well, to avoid newborns pop-out. The Theme- 5 backward side was setted as a work area, while the front side was setted towards the expository pathway. Such solution has made possible to the spectators to see the embryonic development and the sharks newborns since few days from hatching. It is possible to observe all the entire system. Where the water flow was passing first from the bottom and surface skimmers, then to the treatment machinery over passing 3 external pumps (P1, P2 and P3), having a flow rate of $32 \mathrm{~m}^{3}$. P1 and P2 were forcing the water flow towards 2 mechanic filters, then in a UVC sterilizer, a warm exchanger and finally to feed the biological filter. P3, instead, was forcing a predetermined part of water to a protein-skimmer. Besides, in parallel with the biological filter flow there was the heating and cooling system which maintained the temperature of the water, constantly monitored, at $24.5 \pm 0.5^{\circ} \mathrm{C}$.

Therefore, water parameters were kept under control through periodic replacement procedures (make-up, MU) which included adding pre-filtered water from aquarium seacock. Salinity was placed under control by freshwater-MU. Weekly water analysis has been conducted paying attention to temperature, salinity, $\mathrm{pH}$, ammonia, nitrites, nitrates and phosphates by a spectrophotometer and a multiparameter sonde. Regarding the lighting system of T5, it was illuminated with 2 lighthouses with the same power at $400 \mathrm{~W}$, but with different color temperature: the dark side at $20.000^{\circ} \mathrm{K}$ with an illuminance value of $2.5 \mathrm{~lx}$ and the light side at $10.000{ }^{\circ} \mathrm{K}$ with illuminance value of $5 \mathrm{~lx}$. The Themes- 5 was illuminated by four neon lamps with power at $36 \mathrm{~W}$. Thus, in order to set up the light gradient, they were used light filters placed on the anti-skips that have allowed obtaining specific lux value per each theme tray. Every value was measured by a Lux-meter, useful instrument that is measuring the illuminance of a surface in lux (lumen $\left./ \mathrm{m}^{2}\right)$. The light gradient was setted with the following values: Th $1=11 \mathrm{x}-\mathrm{Th} 2=2.51 \mathrm{x}-\mathrm{Th} 3=3.71 \mathrm{x}$ - Th4=51x $-\mathrm{Th} 5=101 \mathrm{x}$, paying attention to the C. punctatum life environment strongly featured from illuminance variations. ${ }^{24-26}$ Indeed it is a demersal shark living in the water column into the euphotic zone where the illuminance gradient has a range with $\operatorname{lux}_{\min }=1 \%$ of lux ${ }_{\max }$ (Figure 4). ${ }^{24,27}$ Thus, they were replicated the illuminance value of 2 sides of T5 in Th2 and Th4 and assigning to: Th3 the average illuminance value between Th2 and Th4, to Th5 the double illuminance value of Th4 and to Th1 the $1 \%$ of Th5. Afterward, it was necessary to define good diagnostic tools to assess the reproductive events using multimedia materials (photo/video). Thus, it was possible to document directly courtship and breeding. Instead, to assess the life stages was necessary the eggs clean up to make them translucent. Once did it, it has been possible to define 6 different life stages during the embryonic development: 1)Egg stage [only yolk sac visible]; 2) Little embryo; 3) Medium embryo; 4) Big embryo; 5) Newborn; 6) Adult; in base of different morphological and biometrical features referenced: presence/absence of a visible embryo ${ }^{28}$ relative size of embryo to the yolk sac ${ }^{28,29}$ presence/absence of banded skin pattern and specimens length and weight. ${ }^{29}$ The adults of $C$. punctatum were feeded following the standard schedule Acquario di Cattolica's aquariological sector. Hence, the feeding occurred 3 times with codfish, shrimp, mackerel and squid by doses equal at $4-6 \%$ of the live-weight. ${ }^{8}$ In order to wean the newborn, they were following a specific diet based on data in Table 2 and composed from shrimp (Pandalus borealis), capelin (Mallotusvillosus), codfish (Merlucciusmerluccius) and mackerel (Scomberscombrus) and the quantity dosed to the newborn was equal at $5 \%$ of their body-weight (BW) multiplied per a modifier equal at 3 times the BW per week. ${ }^{8}$ Besides, every week was dosed vitamins for shark Nutrazu ${ }^{\circledR}$ shark/ray. Growth assessment required to operate by aquarium technical procedures to manage the animals $\mathrm{s}^{30}$ measuring the total length (TL), by a common millimeter meter absorbed in a translucent water tray for the newborn meanwhile through the use of a centimeter basket for the adults and body weight (BW), by a precision balance $(\mathrm{d}=0.001 \mathrm{~g})$ calibrating a water tray and through a dynamometer $(\mathrm{d}=0.01)$ calibrated by a water container. Every biometrical measure on newborn has been carried out in triplicate $(n=3)$ and in different times during the day $\left(r_{1}, r_{2}\right.$ and $\left.r_{3}\right)$. Instead the biometry of adults was measured in a unique solution $(n=1)$.

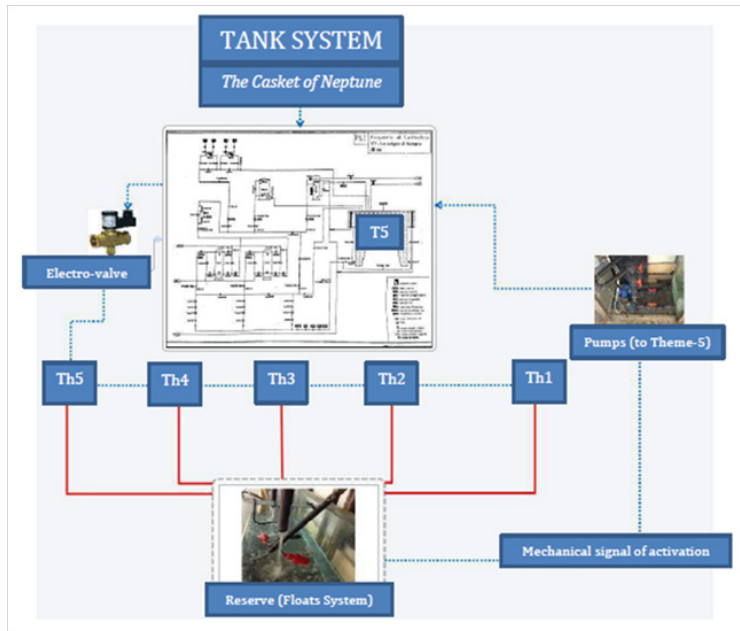

Figure I Tank system. The main tank (T5) was getting out the water in Theme-5 trays system through an electro-valve and filtered through the complex filtering system in the white square. Therefore the 5 trays were pump out the water in T5 through a floats system using mechanical pumps. 


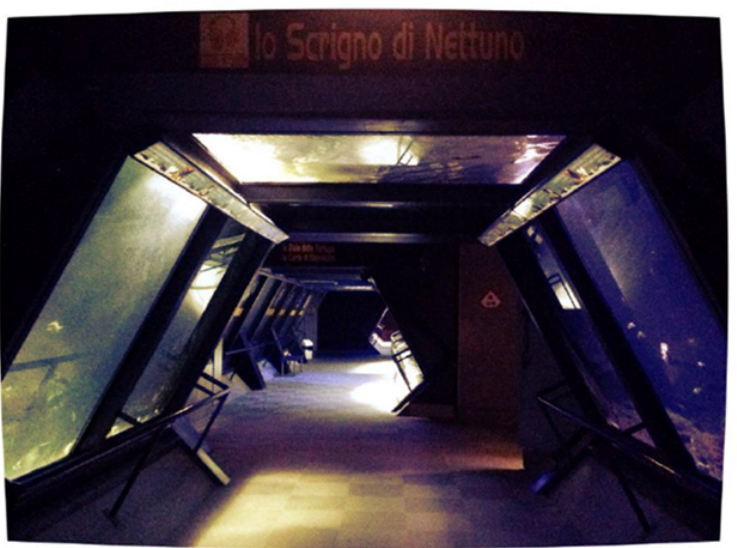

Figure 2 The two sides of "The Casket of Neptune"(T5) inside the "blu pathway" of Acquario di Cattolica.
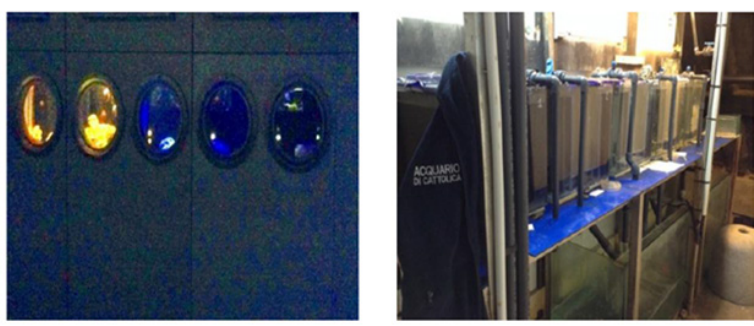

Figure 3 Front side (left) and work backward area (right) of "Nursery themes" (Theme-5) inside the "blu pathway" of Acquario di Cattolica.

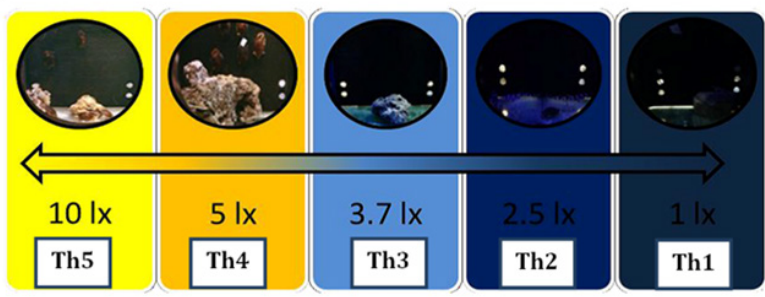

Figure 4 The illuminance gradient obtained in according with the wild-life information available.

\section{Reproductive protocol and experimental designs}

In order to test the experimental hypothesis and to build the reproductive protocol were setted up 1 mind map and 3 experimental designs. The reproductive protocol (Figure 5) purposed is a flow diagram showing the modus operandi activated during the entire period of observations. This protocol was setted up on the crucial event of eggs deposition, indeed starting from this certain data have been defined all steps to handle the reproductive cycle at the best The first experimental design (Figure 6) was setted up to clarify the first hypothesis (1) on embryonic development: they have been used only Th2 (2.51x) and Th4 (51x). These trays hosted 3 eggs (u1, u2 and $\mathrm{u} 3$ ) in total 6 eggs tested. The "d" value represents the deposition date (starting point). Also to define the development times of the 3 embryonic stages (e1, e2 and e3), the eggs were measured constantly monitored during their evolution explain this measure in days post deposition (dpd). The " $\mathrm{H}$ " value represent the hatching moment measured by dpd as well. The second hypothesis on illuminance gradient with constant diet was tested by a second experimental design (Figure 7) assigning two newborns per each tray (101x, 5lx, 3.61x, $2.51 \mathrm{x}, 11 \mathrm{x}$ ) for a total of 10 individuals, one of the two specimens was the control $\left(\mathrm{CT}_{\mathrm{x}}\right)$ while the other was the replicas shark $\left(\mathrm{N}_{\mathrm{x}}\right)$. Thus, were harvested measures of TL and BW in 3 replicas $(n=3)$ per each catch $\left(\mathrm{C}_{\mathrm{x}}\right)$ carried out at the week beginning and per each recapture $\left(\mathrm{R}_{\mathrm{x}}\right.$ and $\left.\mathrm{R}_{\mathrm{x}},{ }_{\mathrm{y}}\right)$ carried out at the week middle and the end, per the 8 subsequent weeks the hatch $(\mathrm{s} 1 \ldots(\mathrm{sx}) \ldots \mathrm{s} 8)$. Finally, the third and fourth hypothesis was tested by a unique experimental design (Figure 8 ), where they were placed under exam 5 newborn ( 3 females and 2 males). The diet was setted up dosing vitamins $(\mathrm{V}=[+]$ vitamins; $\mathrm{NV}=[-]$ vitamins) monthly alternating and meantime the 4 feeds $P$. borealis, S. scombrus, M. villosus and M.merluccius have been dosed weekly alternating. During the first catches $\left(\mathrm{C}_{\mathrm{x}}\right)$ carried out at the week beginning and per each recapture $\left(\mathrm{R}_{\mathrm{x}}\right.$ and $\left.\mathrm{R}_{\mathrm{x}, \mathrm{y}}\right)$ carried out at the week middle and the end, also each data has been sampled in 3 different technical replicas.

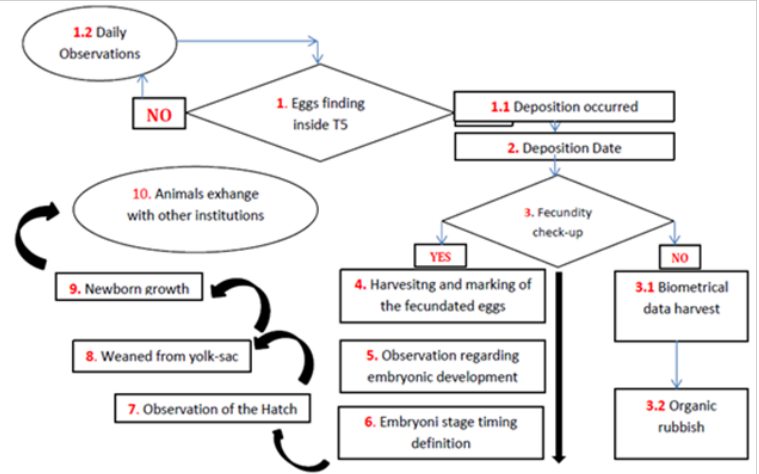

Figure $\mathbf{5}$ This Flow Diagram is showing our daily way to operate which was called: reproductive protocol of $C$. punctatum.

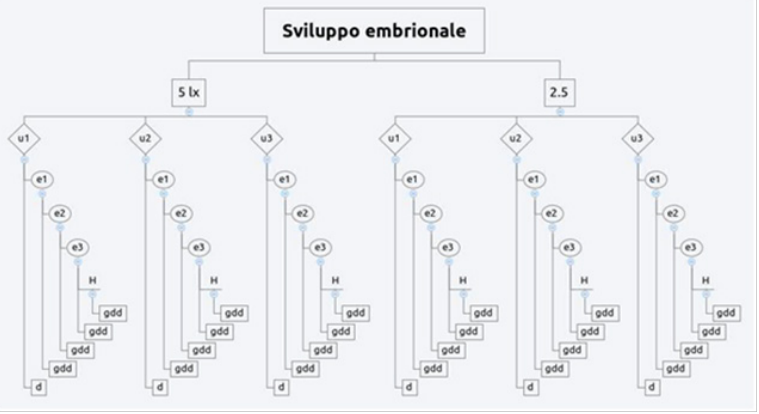

Figure 6 The first experimental design regarding the embryonic development.

5 Ix: Illuminance value of Th4; 2.5 Ix: Illuminance value of Th2; ux: Egg Stage (n:3 per tray); ex: Embryo stages (progressive evolution); H: Hatch; gdd: Day Post Deposition (dpd); d: Deposition Time.

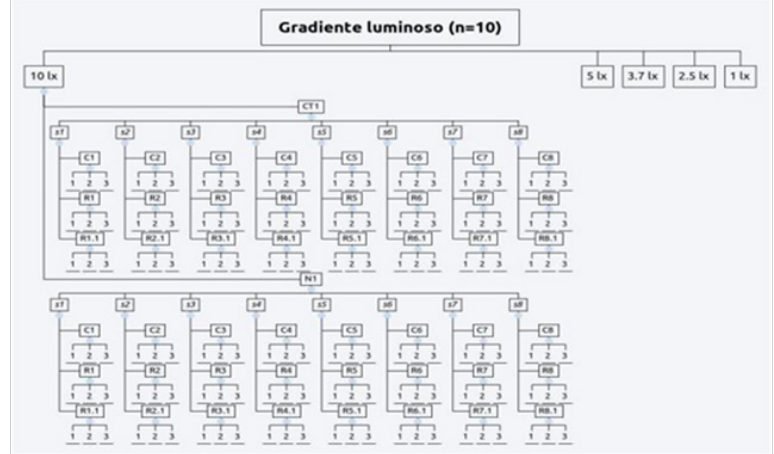

Figure 7 The second experimental design regarding the illuminance gradient.

Theme-5 Illuminane values: I0 Ix; 5 Ix; 3.7 Ix; 2.5 Ix and I Ix; $\mathrm{CT}_{\mathrm{x}}$ : Control Sample; $N_{x}$ : Sample; sx: Times; $C_{x}$ : Captures; $R_{x}$ and $R_{x} ; y$ : First and Second Recaptures; rx:Technical Replicas 


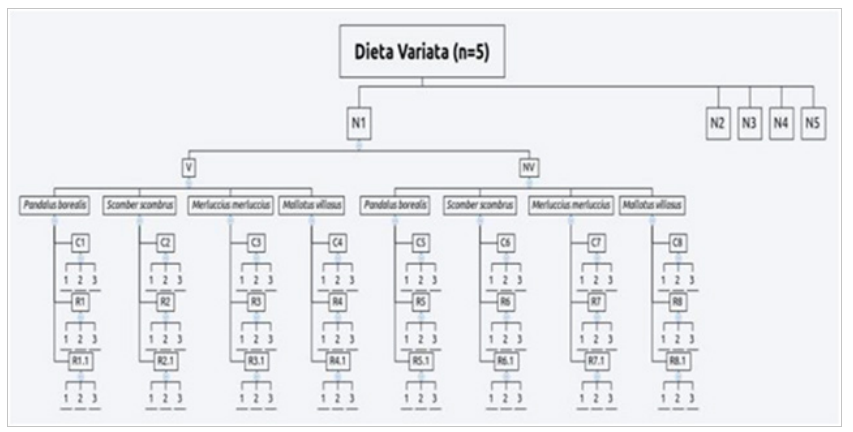

Figure 8 The third experimental design regarding the varied diet.

$\mathrm{N}_{x}$ :Sample;V:Vitamins Presence; NV:Vitamins Absence; P. borealis; S. scombrus; $M$. merluccius and $M$. villosus: Feeds; $C_{x}$ : captures; $R_{x}$ and $R_{x} ; y$ First and Second Recaptures; $r x$ :Tehnical Replicas.

\section{Data analysis}

Data statistical analysis has been carried out through two open source software: FiSAT II (FAO) and Open Stat. Regarding graph analysis we used other two software: Microsoft Excel and RKWard. The most important analytical method used it was based on: the Von Bertalanffy Growth Function (VBGF). ${ }^{31}$

Where to assess and build up the growth curves it was necessary to estimate 3 different parameters: $L$ (i.e. maximum length expected), $\mathrm{K}$ (i.e. growth constant) and t0 (i.e. time which the growth is nothing). Also, other important methods to test the hypothesis and to extract all the necessary information, they were taken from Gulland \& Holt: ${ }^{32}$ the $\mathrm{GH}$ and Residual plot. ${ }^{32}$ At last, to inference statistically the data, it has been used Analysis of Variance (ANOVA) between treatments and subjects (AxS) followed by Tukey's post-hoc method (HSD).

\section{Results}

During data harvesting, they were born 33 C. punctatum's newborn, the $60.61 \%$ of females and the $39.39 \%$ of males; Figure 9 is showing the percentage values of such difference. Afterward, it was measured the biometry of eggs, newborn (males and females) and adults explained in Table 3. A group of 15 specimens on 33 was analyzed to build the graph in Figure 10 that is showing their growth trend (TL). Therefore, it was possible to recognize the great growth difference between newborn male and female. Since $27^{\text {th }}$ January till $17^{\text {th }}$ June 2014, within a total of 139 days, they were dated every deposition event occurred in T5. During this period the adult female deposited 35 eggs depositing approximately 2 eggs per week. The weekly Average Deposition Frequency (ADF) was $2.19 \pm 1$ (ES) eggs, while the monthly ADF was $8.75 \pm 1$ (ES) eggs. Under desired conditions, the egg stage (u) was lasting in average $10.5 \pm 4.4$ days $(n=35)$, so afterward to this development period it was possible to see visualize the embryo by naked eye. The little embryo stage (e1) was lasting in average $16.5 \pm 4$ days $(n=23)$, while the subsequent stage, the medium embryo (e2), was lasting in average $43 \pm 5.5$ days ( $n=15)$ and finally the last embryonic stage, the big embryo (e3), was lasting in average $48 \pm 2.5 \mathrm{gg}(\mathrm{n}=5)$. Thus, the average incubation period of an egg was lasting $117.5 \pm 3.5$ days (approximately 4 months; $n=5$ ). Afterward they are shown the obtained results from the first experimental design (Figure 11). From the others two experimental designs produced the relative VBGFs underline significant differences onsize and timelines to achieve sexual maturity between male and females $(p<0.05)$, as reported by Haraush et al. ${ }^{23}$ Meantime the VBGFs, under gradient light conditions, underlined no significant differences $(p>0.05)$.
Finally, the shrimp (P. borealis: $3 \mathrm{cal} / 1 \mathrm{gr}$ ) resulted the food with the best performances.

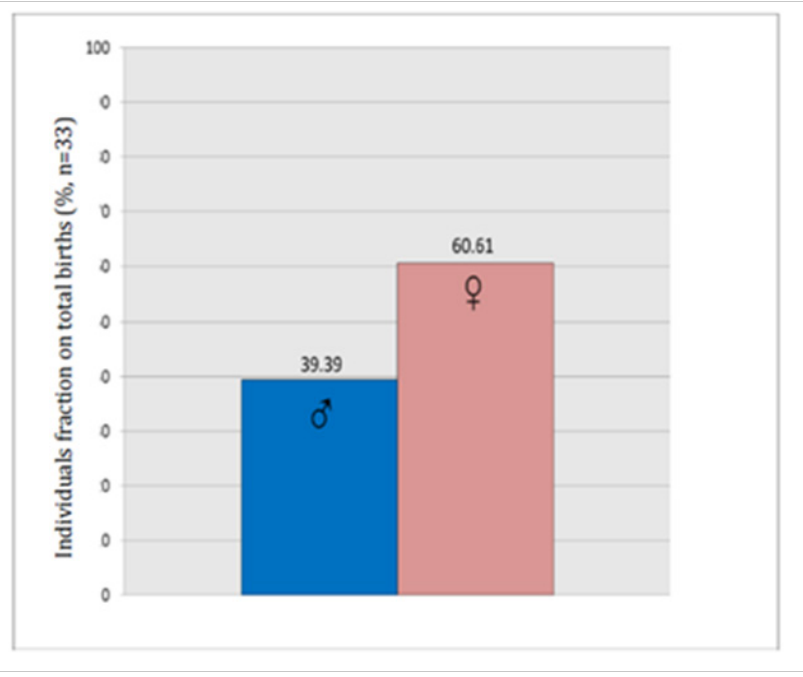

Figure 9 Difference of gender on total births. $39.39 \%$ of males and $60.61 \%$ of female's fraction.

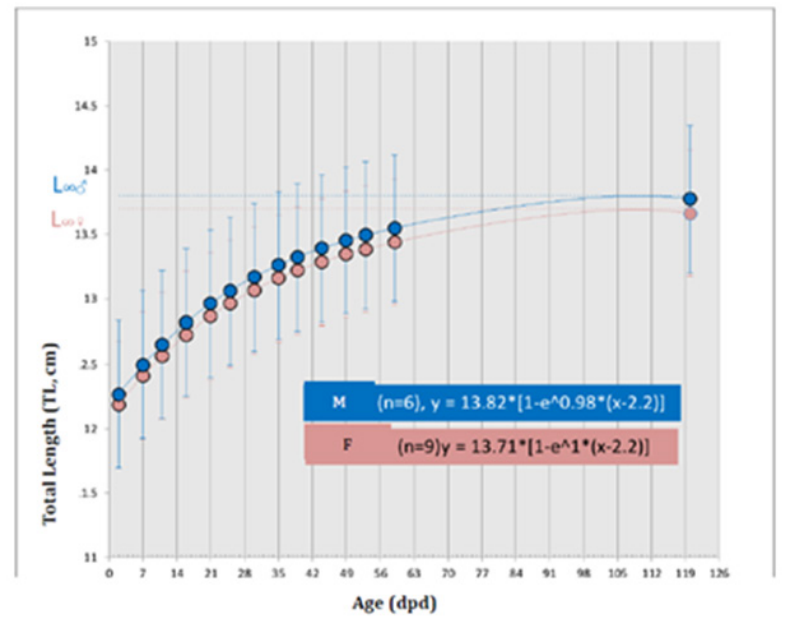

Figure 10 VBGF (TL) of every newborn female and male studied ( $\mathrm{n}: 15$; males $(M): 6$; females $(F): 9 ; p<0.01$ vs females; ANOVA between treatments and subjects by HSD).

\section{Discussion and conclusion}

During this period it was possible to recognize that the limits place from Mohan $\&$ Aiken $^{7}$ in Table 1 are corrects to obtain an aquatic environment similar to the wild habitat of $C$. punctatum. Whom they cannot cohabit with them newborns in the same tank. Because the shark newborn are under attack and also murdered from adults (sentence confirmed during the observations carried out in aquarium at the moment of the release of 4 specimens $20 \mathrm{~cm}$ TL who the aquarists wanted to introduce in the exhibit tank). However, the adults can cohabit quietly with the eggs already hatched and the C. punctatum's newborns can cohabit under high concentration of individuals also in reduced rooms, although this condition it is not valid anymore when also just an egg is inserted in the tank. Because egg protective colloidal filaments are a big dangerous factor for newborns that can entangle themselves dying cause asphyxiation. Instead, the eggs accurately cleaned from colloidal filaments can growth reaching the hatch in tank hosting C. punctatum adults and newborn. Moreover, the 
eggs were always deposited in the rocks accurately tied or hidden in protective shelters.

It results such a crucial observation that piles of rocks must be considered fundamental pillars ${ }^{33}$ to prepare ex novo tanks as a beginning of a reproductive protocol. Constantly observations of the eggs allowed us to assess correctly the reference timing of each embryonic development step. Such data allows a planning of embryo's evolution steps and a correct tank management. Harahush et al. ${ }^{23}$ were working by temperatures at $21-25^{\circ} \mathrm{C}$ and they registered that the embryos are visible, by naked eye, for the first time at 18th day post deposition. This data is against the obtained results (Figure 11) because, under the experimental conditions we setted up $(24.5$ ${ }^{\circ} \mathrm{C}$ constant optimum), the embryos were visible at 10 th day post deposition. Moreover, they ${ }^{23}$ defined in a different way the embryonic stages where the biggest embryos were called in "pre-hatching" and identified around at $35 \mathrm{dpd}$, also in this case the data are in conflict, cause through our experimental conditions the "pre-hatching" stage occurred after $70 \mathrm{dpd}$. At last, Harahush et al. ${ }^{23}$ fixed the hatch time at $153 \mathrm{dpd}$, instead at our conditions it was at $117 \mathrm{dpd}$. This fact is underlining how important is the influence of the temperature during the shark embryonic development. Besides, these development timing were not significantly induced from different illuminance conditions tested (Figure $11-\mathrm{p}>0.05$ ). The most of the eggs deposited were found inside the lighter part of T5. This observation is also important cause allows to the technicians to build a suitable environment to favor the deposition. Afterwards, on 33 newborns the se x-ratio has been of 6:4 with female sex dominance. On 6 males and 9 female $(\mathrm{n}=15)$ were calculated the relative average growth functions (VBGF) whom resulted to be significantly different between them (Fi.9.5, p $<0.01)$. Such data agree with $C$. punctatum's sex size data provided from Harahush et al. ${ }^{23}$ where males are reaching sexual maturity around $68-73 \mathrm{~cm}$ TL having bigger size than females, which are reaching their sexual maturity at $63 \mathrm{~cm}$ TL.A varying diet was dosed to 5 C. punctaum's newborn, Thus, through the Residual plot $^{32}$ it was possible to show the GRs values fluctuations in time (Figure 12). The parameter $\mathrm{C}>1$ underline how the differences between GRs generated from different foods weekly dosed are wide and significantly different. Whereas every week it has been varied the feed kind, the shark puppets were growing differently in dependence with the dosed feed. Indeed, the obtained data from shrimp (genus: Pandalus spp.) dosing has provided a greater rate (Figure $13-\mathrm{p}<0.05$ ) than the others dosed feeds: mackerel (S. scomber), capelin (M. villosus) and codfish (M. merluccius). This result is concordant with the high acceptance explained from a part of newborns over this feed; energetic values in Table 2: per 1 gram of feed: shrimp $=3 \mathrm{cal}$; mackerel $=2 \mathrm{cal}$; capelin $=2 \mathrm{cal}$ and codfish $=1 \mathrm{cal}$. Such values are concordant with bibliography references regarding the wild co-specific diet of $C$. punctatum, whom are feeding with little invertebrates as crabs or shrimp. ${ }^{2,34}$

Table 2 Nutritional values per feed (Data from: Calorie Slism database 20l4: http://slism.com/calorie)

\begin{tabular}{lllll}
\hline Feeds & Nutritional Values & & C (cal) & T (cal /g) \\
\hline Pandalus borealis & $\mathbf{P}$ (cal) & F (cal) & 0 & 3 \\
Scomberscombrus & 2.6 & 0.56 & 0 & 2 \\
Mallotusvillosus & 0.84 & 1 & 0.04 & 2 \\
Pandalus borealis & 0.66 & 1 & 0 & 1 \\
\hline
\end{tabular}

P: Proteins; F: Fats; C: Carbohydrates; T:Total Nutritional Value; Cal: Calories; cal/g: Calories Per Gram

Table 3 C. punctatum's biometrical values

\begin{tabular}{|c|c|c|c|c|c|c|}
\hline \multirow{4}{*}{ C. punctatum's Life Stages } & \multicolumn{6}{|c|}{ Biometrical Values } \\
\hline & \multirow{2}{*}{\multicolumn{2}{|c|}{$\begin{array}{l}\mathrm{TL} \\
\mathrm{cm}\end{array}$}} & \multicolumn{4}{|l|}{ BW } \\
\hline & & & $g$ & & $\mathrm{Kg}$ & \\
\hline & $\mu$ & $\pm S D$ & $\mu$ & $\pm S D$ & $\mu$ & $\pm S D$ \\
\hline Eggs [ $n=23$; dried weight] & 5.36 & 0.17 & 1.39 & 0.16 & - & \\
\hline Total Newborn [ $n=18]$ & 12.17 & 0.36 & 8.07 & $0.4 I$ & - & \\
\hline Newborn $\widehat{\partial}[n=8]$ & 12.25 & 0.35 & 7.98 & 0.54 & - & \\
\hline Newborn $q[\mathrm{n}=10]$ & 12.13 & 0.32 & 8.13 & 0.38 & - & \\
\hline Total adults $[n=2]$ & 68 & I & - & & 1.3 & 0.28 \\
\hline Adult $\lesssim[n=I]$ & 7I & 0.5 & - & & 1.5 & 0.14 \\
\hline Adult $+[\mathrm{n}=1]$ & 65 & 0.5 & - & & I.I & 0.14 \\
\hline
\end{tabular}

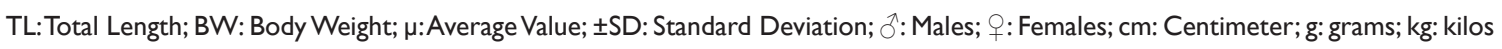

Subsequently, they have been taken under exam 10 newborns weaned by a constant diet (shrimp) to evaluate the illuminance influence on growth. The 10 shark babies $(n=10)$, placed in couples $\left(\mathrm{CT}_{\mathrm{x}}+\mathrm{N}_{\mathrm{x}}\right)$ under different illuminance conditions (Figure 4) have not shown to be influenced from the light during their growth. Because the observed differences are not significant (Figure $14-\mathrm{p}>0.05$ ). During this trial, it was observed a greater stress, breathlessness and feeding frenzy behavior frequency on the newborns hosted in the trays with the higher illuminance values: Th $5=101 \mathrm{x}$ and Th $4=51 \mathrm{x}$. Inside the others trays the newborn specimens had more natural behavior. For this reason become intuitive to state that lowly illuminance values $(\mathrm{X}<51 \mathrm{x})$ are maintaining newborn under better conditions than highly illuminance values $(X>3.7)$ which can confuse the animals. Considering the BW data, it is considerable how the 5 newborn weaned from yolk-sac by varying diet are presenting an unstable $\mathrm{BW}$ trend and irregular than $\mathrm{BW}$ trend of 10 processed newborn by a constant diet.

Therefore, the dosing of a quality constant diet during the first growth steps is strongly suggested in order to obtain better nutritional buoyancy, so avoiding newborn BW fluctuations. Breeding occurred continuously, due to constant and perfect water, tank room and illuminance conditions: inside the 5lx parts were deposited the eggs, while in 2.51x part the female had her shelter zone. Deposition was regular during all the observation period with average frequencies 
around 2 eggs/week and almost 9 eggs/month. Regarding the obtained percentages of mortality we underline the most sensitive phases: the egg stage (U) with a $49 \%$ and the little embryo stage with a $31 \%$. Besides, the time threshold, past which there were not prenatal mortality events, has been registered around at $27^{\text {th }}$ day post deposition. Under the experimental conditions setted the $C$. puntatum development was lasting around 4 months since deposition date. Proposing the experimental hypothesis placed, we conclude:

a. Normal embryonic development timing and hatching are not significantly influenced from a light gradient.

b. The newborn growth is not significantly influenced from illuminance. In figure 14 is possible to appreciate the growth curves obtained, where the observable differences are stochastic ( $>00.05)$.

c. Dosing of different feeds influences significantly the newborn growth. The best feed to wean from the yolk-sac resulted to be $P$. borealis (shrimp).

d. Vitamins are not significantly influencing the newborn growth during the weaned period, cause we think is a too brief time to appreciate a significant data variation.

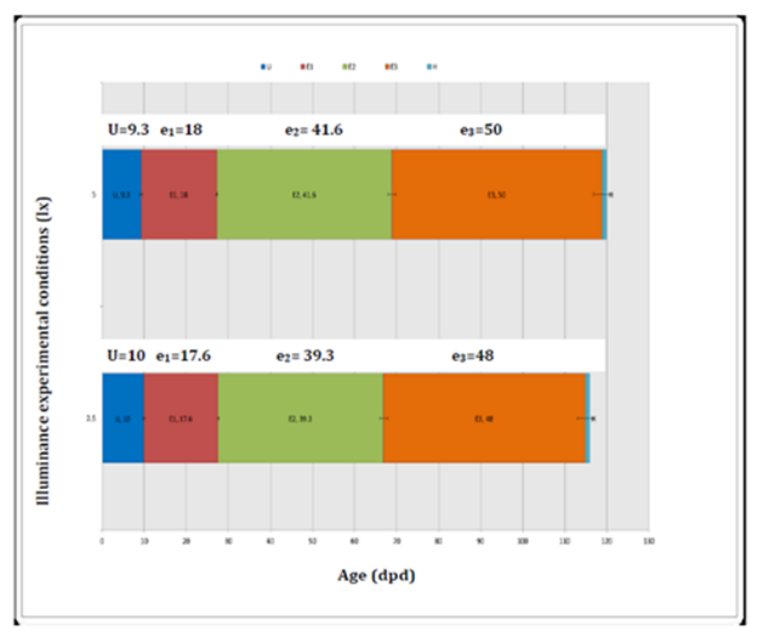

Figure I I Average embryonic development timing under different illuminance conditions. The graph is showing the average embryonic development timing \pm standard error (ES; $p>0.05$ vs Th 2-[2.51x]; ANOVA between treatments and subjects by HSD test).

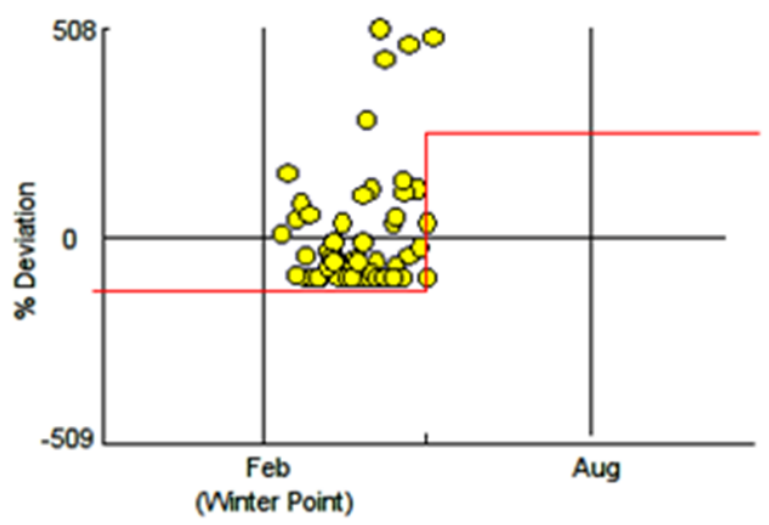

Figure 12 Residual plot. ${ }^{32}$ Deviation between yellow spots and growth rates underline the wide and significant $(C>I)$ differences observed during the varied diet dosing.

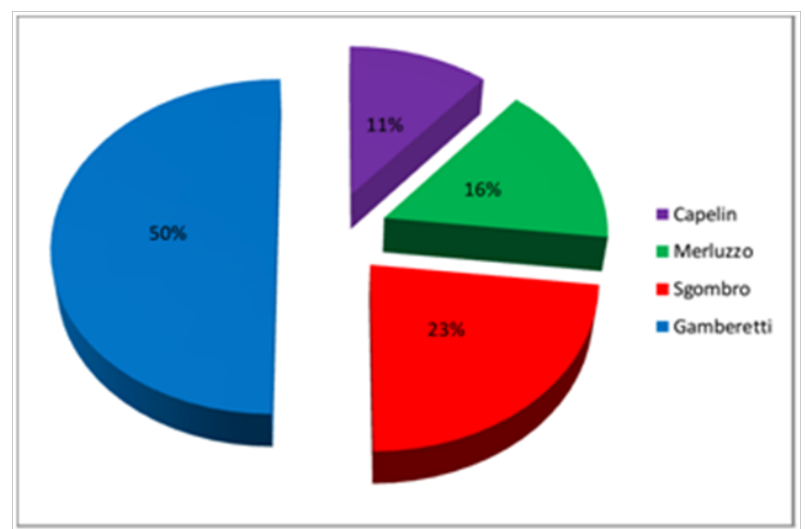

Figure 13 Percentage grant to the growth of each feeds on 4 selected [50\% shrimp (blue)] and dosed during 2 months after the hatch $(n: 5 ; p<0.05$ vs capelin (violet); codfish (green) and mackerel (red); ANOVA between treatments and subjects by HSD test).

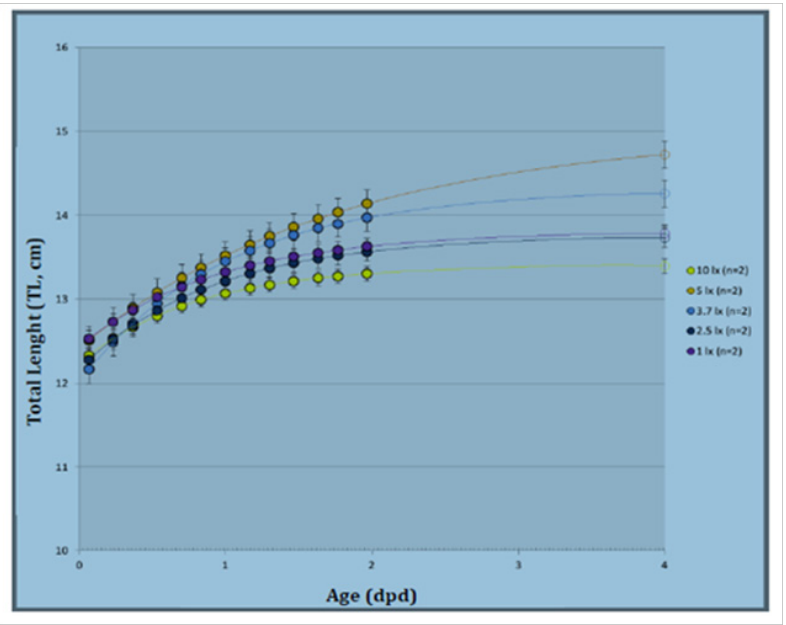

Figure I 4 VBGF (TL) average (n: 10) \pm ES of newborn weaned from yolk-sac under different illuminance conditions. Every VBGF is showing the newborn growth; 2 per tank at illuminance value predetermined $(\mathrm{n}: 10$; $>>0.05$ vs $3.7 \mathrm{~lx}$; I Ix; 2.5 Ix and I0 Ix;ANOVA between treatments and subjects by HSD test).

In conclusion, to obtain a correct management and the reproduction of $C$. punctatum is strongly suggested to use 2 different types of tanks. A tank of big size which will host the adults and a second tank in reduced size will host the newborn. The eggs have to be managed between two systems, accurately prepared and monitored during embryonic development. A different illuminance of couple tank seems to be an important factor influencing the reproductive behaviors at the adult stage. While it seems not inducing the growth and embryonic development neither. In order to wean the newborn during their first growth steps is suggested to use only a type of feed and the shrimp result to be a optimal and inexpensive feeding source. Shark newborn, even if they are not influenced from different illuminance conditions during the growth, has need of an illuminance lower than $5 \mathrm{~lx}$ to avoid stress behavior. In general C. puntatum is a species with a coy behavior, with a high resilience to water parameter variations (great resistance to hypoxia), it is easy to manage and with high reproductive potentiality in controlled environment. Therefore, this is a species that lends itself to eventual controlled reproductive projects which must be supervised and managed in appropriate manner paying consideration on that is reported here. 


\section{Acknowledgements}

This study was made possible by the agreement between the University of Bologna and Acquario di Cattolica is therefore due the acknowledge to all the staff members and the technicians who worked for its implementation: Dr. Gridelli S., Dr. Florio D., Dr. Ferri A., Dr. Canini S., Dr. Bordoni P., Dr. Trappetti A., Dr. Da Rugna C., Domenichelli F., Fuzzi S., Dr. Bargnesi F., Farroni T., Prof. Mordenti O., Gori D., Calcinelli C., Pascucci D. and Tinti F.

\section{Conflicts of interest}

None.

\section{References}

1. Hutchins M. Zoo and aquarium animal management and conservation: current trends and future challenges. International Zoo Yearbook. 2003;38(1):14-28.

2. Bennett MB, Kyne PM. Chiloscyllium punctatum. SSG Australia e Oceania Regional Workshop di IUCN Red List of Threatened Species, Australia. 2003.

3. Wass RC. Size, growth and reproduction of the sandbar shark, Carcharhinus milberti in Hawaii. Pac Sci. 1973;27(4):305-318.

4. Pauly D. Theory and management of tropical multispecies stocks. ICLARM studies and reviews. 1979;1:35.

5. Casey JG, Pratt HL, Stillwell CE. Age and growth of the sandbar shark (Carcharhinus plumbeus) from the western North Atlantic. Can J Fis Aqu Sci. 1985;42(5):963-975.

6. Branstetter S, McEachran JD. A first record of the Odontaspisnoronhai (Lamniformes: Odontaspididae) for the western North Atlantic, with notes on two uncommon sharks from the Gulf of Mexico. NEast Gulf Sci. 1986;8(2):153-160.

7. Mohan PJ, Aiken A. Chapter 6. The Elasmobranch Husbandry Manual: Captive Care of Sharks, Rays and their Relatives. In: Smith et al. (Eds.), Ohio Biological Survey, Columbus, Ohio, USA. 2004;p.69-88.

8. Janse M, Firchau B, Mohan PJ. Chapter 14. The Elasmobranch Husbandry Manual: Captive Care of Sharks, Rays and their Relatives. In: Smith et al. (Eds.), Ohio Biological Survey, Columbus, Ohio, USA. 2004;pp.183-200.

9. Horn MH. The Physiology of Fishes, Chapter 3. In: Evans et al. (Eds.), CR Press, Boca Raton, New York, USA. 1998;pp.519.

10. Crow GL, Luer WH, Harshbarger JC. Histological Assessment of Goiter in Elasmobranch Fishes. J aquatic Animal Health. 2001;13:1-7.

11. Crow GL. Chapter 28. The Elasmobranch Husbandry Manual: Captive Care of Sharks, Rays and their Relatives. In: Smith et al. (Eds.), Ohio Biological Survey, Columbus, Ohio, USA. 2004;pp.441-446.

12. Crow GL, Brock JA. Chapter 30. The Elasmobranch Husbandry Manual: Captive Care of Sharks, Rays and their Relatives. In: Smith et al. (Eds.), Ohio Biological Survey, Columbus, Ohio, USA. 2004;pp.467-472.

13. Mohan PJ, Clark ST, Schmid TH. Chapter 15. The Elasmobranch Husbandry Manual: Captive Care of Sharks, Rays and their Relatives In: Smith et al. (Eds.), Ohio Biological Survey, Columbus, Ohio, USA. 2004;pp.201-226.

14. Uchida S, Toda M, Kamei Y. Elasmobranchs as Living Resources: Advances in the Biology, Ecology, Systematics, and the Status of the Fisheries. NOAA Technical Report NMFS. 1990;90:211-237.

15. Van Dykhuizen G, Mollet HF. Growth, age estimation and feeding of captive seven-gill sharks, Notorynchus cepedianus, at the Monterey Bay Aquarium. Marine and Freshwater Research. 1992;43(1):297-318.
16. Murru FL. The care and maintenance of elasmobranchs in controlled environments. Elasmobranchs as Living Resources: Advances in Biology, Ecology, Systematics, and the Status of Fisheries. NOAA Technical Report NMFS. 1990;90:203-209.

17. Henningsen AD, Smale M, Garner R, et al. The Elasmobranch Husbandry Manual: Captive Care of Sharks, Rays and their Relatives. In: Smith et al. (Eds.), Ohio Biological Survey, Columbus, Ohio, USA. 2004;pp.227-236.

18. Choromanski JM. The Elasmobranch Husbandry Manual: Captive Care of Sharks, Rays and their Relatives. In: Smith et al. (Eds.), Ohio Biological Survey, Columbus, Ohio, USA. 2004;p.43-51.

19. Camhi MD, Valenti SV, Fordham SV, et al. The Conservation Status of Pelagic Sharks and Rays. Tubney House. 2007;1(1):1-78.

20. Nelson DR, Johnson RH. Diel activity rhythms in the nocturnal, bottom-dwelling sharks, Heterodontus francisci and Cephaloscyllium ventriosum. Copeia. 1970;1970(4):732-739.

21. Moe MA. The marine aquarium handbook: beginner to breeder. Green Turtle Publications, USA. 1992;pp.320.

22. Müller J, Henle FGJ. On the generic characters of cartilaginous fishes, with descriptions of new genera. Magazine of Natural History. 1838;2(3):34-37.

23. Harahush BK, Fischer ABP, Collin SP. Captive breeding and embryonic development of Chiloscyllium punctatum Muller \& Henle 1838(Elasmobranchii: Hemiscyllidae). J Fish Biol. 2007;71(4):10071022 .

24. Gordon JDM, Bergstad OA, Pascoe PL. The influence of artificial light on the capture of deep-water demersal fish by bottom trawling. J Mar Biol Ass UK. 2002;82(2):339-344.

25. Compagno LJV, Ebert DA, Cowley PD. Distribution of offshore demersal cartilaginous fish (Class Chondrichthyes) off the west coast of southern Africa, with notes on their systematics. South African Journal of Marine Science. 1991;11(1):43-139.

26. Compagno LJV. Shark of the World: An Annotated and Illustrated Catalogue of Shark Speies Know to Date. FAO Species Catalogue. 1984;4(2):251-553.

27. Thurman EM. Determination of aquatic humic substances in natural waters. US Geol Surv Pap Hydrol Sci. 1983;22(62):47-52.

28. Mojetta A. Squali. Le Guide White Star Immersioni, Vercelli, Italy. 2004;pp.167.

29. Compagno LJV, Niem VH. The living marine resources of the Western Central Atlantic. FAO. 2002;1:1194-1207.

30. Marshall A. The Elasmobranch Husbandry Manual: Captive Care of Sharks, Rays and their Relatives. In: Smith et al. (Eds.), Ohio Biological Survey, Columbus, Ohio, USA. 2004;pp.89-103.

31. Von Bertalanffy L. A quantitative theory of organic growth (inquiries on growth laws. II). Human biology. 1938;10(2):181-213.

32. Gulland JA, Holt J. Estimation of growth parameters for data at unequal time intervals. J Mar Sci. 1959;25(1):47-49.

33. Powell DC, Wisner M, Rupp J. The Elasmobranch Husbandry Manual: Captive Care of Sharks, Rays and their Relatives. In: Smith et al. (Eds.), Ohio Biological Survey, Columbus, Ohio, USA. 2004;p.54-69.

34. Compagno LJV. Sharks of the world. An annotated and illustrated catalogue of shark species known to date.Bullhead, mackerel and carpet sharks (Heterodontiformes, Lamniformes and Orectolobiformes). FAO Species Catalogue for Fishery Purposes. 2001;2(1):269. 